\title{
Tropical Cyclone as a Possible Remote Controller of Air Quality over South Korea through Poleward-Propagating Rossby Waves ${ }^{\mathscr{O}}$
}

\author{
DOO-SUN R. PARK \\ Department of Earth Sciences, Chosun University, Gwangju, South Korea \\ CHANG-HOI HO AND DASOL KIM \\ School of Earth and Environmental Sciences, Seoul National University, Seoul, South Korea \\ NAM-YOUNG KANG \\ National Typhoon Center, Korea Meteorological Administration, Jeju, and Department of Geography, \\ Kyungpook National University, Daegu, South Korea \\ YEOJIN HAN AND HYE-RYUN OH \\ School of Earth and Environmental Sciences, Seoul National University, Seoul, South Korea
}

(Manuscript received 7 March 2019, in final form 1 October 2019)

\begin{abstract}
Air quality depends as much on large-scale tropospheric circulation as on the amount of pollutant emissions. Many studies have found a relationship between air quality and midlatitude synoptic weather systems. A stable low-level troposphere and airflow from polluted areas are conditions that favor air pollution in a region. However, few studies have focused on the possible remote effect of tropical cyclone (TC) activity in the tropics on air quality in the midlatitude East Asian countries. Here, we found that TCs in the South China Sea (SCS) can increase the concentration of particulate matter with aerodynamic diameters less than $10 \mu \mathrm{m}$ $\left(\mathrm{PM}_{10}\right)$ over South Korea through poleward-propagating Rossby waves. According to our analyses, intense divergence due to a TC causes a barotropic Rossby wave train from the SCS to the North Pacific Ocean. Anomalous highs over the Korean Peninsula (part of the Rossby wave train) result in stable air conditions and cause polluted air inflow to increase the $\mathrm{PM}_{10}$ concentration up to $65 \mu \mathrm{g} \mathrm{m}^{-3}$. Our finding suggests that TC activity in the tropics should be considered for more accurate forecasts of air quality in South Korea.
\end{abstract}

\section{Introduction}

Air quality is an important social issue receiving great attention from scientific circles as well as the public because of its potential for extensive adverse effects on human society and natural systems. For example, both short-term and long-term exposures to particulate matter with aerodynamic diameters less than $10 \mu \mathrm{m}$ in diameter $\left(\mathrm{PM}_{10}\right)$ can cause respiratory and cardiovascular diseases (Pope and Dockery 2006; Li et al. 2018). It was reported that bad air quality causes approximately

Supplemental information related to this paper is available at the Journals Online website: https://doi.org/10.1175/JAMC-D-19-0058.s1.

Corresponding author: Chang-Hoi Ho, hoch@cpl.snu.ac.kr
0.8 million premature deaths worldwide (Anderson et al. 2012). Approximately 3\% of cardiopulmonary and $5 \%$ of lung cancer deaths are attributable to $\mathrm{PM}_{10}$ globally (Shin 2007). Polluted air also has negative effects on visibility, mechanical facilities, and vegetation (Harrison and Yin 2000; Hong et al. 2002; Lau et al. 2008; Hyslop 2009), all of which are tightly associated with our daily lives. Camino et al. (2015) showed that daily mean visibility ranges from 4 to $74 \mathrm{~km}$ according to daily mean $\mathrm{PM}_{10}$ (from 10 to $315 \mu \mathrm{g} \mathrm{m}^{-3}$ ). Particles deposited on plants can block photosynthesis, respiration, and transpiration, thereby resulting in injury and decreased productivity (Farmer 1993). In addition, anthropogenic air pollutants change the radiation budget through direct and indirect effects and consequently affect local climate (Huang et al. 2006, 2007; Jiang et al. 2013; Oh et al. 2013; Chen et al. 2016). 
A number of studies have argued that the events of extremely high concentrations of $\mathrm{PM}_{10}$ over a region are significantly attributable to a long stay of an anomalous high pressure system there, although emission of air pollutants is the main source of poor air quality over East Asia (e.g., Lee et al. 2011, 2013; Seo et al. 2017, 2018; Oh et al. 2018). The limited vertical mixing under the anomalous high prevents air pollutants from spreading out and causes them to accumulate within the boundary layer. In South Korea, when an omega-shaped high develops over Alaska and decelerates the zonal flow of weather systems, a high pressure system can linger over South Korea to cause multiday haze (Seo et al. 2017). A recent study also suggested that weakened zonal flow due to the deepening of the Aleutian low is responsible for a long stay of high pressure over the Korean Peninsula, resulting in poor air quality (Oh et al. 2018).

This high-pressure-origin high- $\mathrm{PM}_{10}$ episode likely occurs regardless of seasons (Seo et al. 2018). In other words, if there is any factor that makes a high pressure system linger over an area, a high- $\mathrm{PM}_{10}$ event could occur. Several recent studies have proposed tropical cyclones (TCs) as a possible factor in the development of bad air quality in summer by keeping stable air conditions in place. Lee et al. (2013) suggested that the extraordinarily long haze event recorded from 15 to 20 October 2008 over South Korea was due to a stagnant high system, the eastward propagation of which was hindered by TC Bavi. Other studies have shown a more direct effect of TCs on air quality. Generally, air conditions become stable right before a $\mathrm{TC}$ reaches a region because of the dominant descending motion surrounding the TC (Feng et al. 2007; Chow et al. 2018; Liu et al. 2018). In some cases, airflow from polluted areas like industrial megacities can become predominant according to the angle from which the TC approaches (Yang et al. 2012; Chow et al. 2018). Under these conditions, air pollutants can accumulate significantly in a region. Although previous studies found a possible TC effect on air quality, the investigation on the effect was limited to within the peripheral circulation of the TC. Few studies, however, looked into possible remote effects of TCs on the air quality in midlatitude countries.

The large-scale circulation in the midlatitudes of East Asia (i.e., the Korean Peninsula and Japanese islands) can be modulated by a poleward-propagating quasistationary Rossby waves originating from tropical convection. The representative one is known as the Pacific-Japan (PJ) pattern described as a wave train from the Philippines to Japan with a 10-50-day period (Nitta 1987; Li et al. 2014). According to Nitta (1987), northwest-westward-propagating convections activate wave trains with horizontal scales of $2000-3000 \mathrm{~km}$ and $1000 \mathrm{~km}$ in the zonal and meridional directions, respectively. He also suggested that a TC is one of such convections. Because a TC is generally accompanied by strong convection and consequent massive precipitation, it can act as a tropospheric heat source in the tropics. Actually, a TC can excite the PJ pattern and remotely affect the rainy season over Japan (Kawamura and Ogasawara 2006; Yamada and Kawamura 2007). Similarly, if a highanomaly phase of the Rossby waves excited by a TC lingers in a region, air circulation can become favorable for air pollution therein. This study investigated whether TCs can affect air quality over South Korea through the Rossby waves using data on the $\mathrm{TC}$ and $\mathrm{PM}_{10}$ concentration.

\section{Data and method}

\section{a. Data}

$\mathrm{PM}_{10}$ concentration data over South Korea were obtained from the Korea Environment Corporation. These data provide the hourly $\mathrm{PM}_{10}$ concentration (unit: $\mu \mathrm{g} \mathrm{m}^{-3}$ ) measured at 271 stations within the country. The mean $\mathrm{PM}_{10}$ concentration of all the stations was used as a proxy of the air quality over South Korea. To exclude the high frequency of $\mathrm{PM}_{10}$ variations, such as a semidiurnal cycle reported by a previous study (Ghim et al. 2015), the low-pass filter based on $24 \mathrm{~h}$ was applied. We only utilized the $\mathrm{PM}_{10}$ data at $0000,0600,1200$, and 1800 UTC since the TC data issued by the Joint Typhoon Warning Center provide information at the same UTCs about TC locations and intensities over the western North Pacific (WNP). Only TCs stronger than $17 \mathrm{~m} \mathrm{~s}^{-1}$ were considered in the analysis. The analysis period in this study covers the TC seasons (JuneNovember) of the WNP from 2001 to 2016. Consequently, the total number (374) of TCs that formed over the WNP were examined. To analyze large-scale tropospheric anomaly patterns, the European Centre for Medium-Range Weather Forecasts interim reanalysis was utilized, of which temporal and horizontal resolutions are $6 \mathrm{~h}$ and $0.7^{\circ}$, respectively (Dee et al. 2011). The anomalies were defined as the deviations from climatological seasonal cycle with 6-hourly intervals.

\section{b. Barotropic model}

A simple barotropic model was used to simulate Rossby wave patterns induced by tropical convections. The barotropic model applied in this study is the same as that used in Held and Kang (1987) except for the divergence forcing term. The model solves the following equation for conservation of absolute vorticity by the spectral method with rhomboidal truncation at wavenumber 15: 


$$
\frac{\partial \zeta^{\prime}}{\partial t}=-[\mathbf{V} \cdot \nabla(f+\zeta)]^{\prime}-[(f+\zeta) D]^{\prime}+T^{\prime}-\kappa \zeta^{\prime}+\nu \nabla^{4} \zeta^{\prime}
$$

where $\zeta$ is the relative vorticity, $\mathbf{V}$ is the horizontal wind vector with zonal and meridional components, $f$ is the Coriolis parameter, $D$ is the horizontal divergence, $T$ is the transients, $\kappa$ is the damping coefficient, and $\nu$ is the biharmonic diffusion coefficient. The prime indicates deviation from the zonal mean. This equation consists of advection, divergence, transient, damping, and diffusion terms. The divergence term is related directly to the source of the Rossby waves. The geographical location and magnitude of the divergence term can determine the propagation of Rossby waves, which will be covered in the following section. The transient term that determines time-mean vorticity tendency is calculated from the basic flow by the expression $\nabla \cdot\left[\left(f+\zeta_{\text {basic }}\right) \mathbf{V}_{\text {basic }}\right]$ (Held and Kang 1987), where the basic relative vorticity $\left(\zeta_{\text {basic }}\right)$ and flow $\left(\mathbf{V}_{\text {basic }}\right)$ are obtained from climatological mean flow at the $850-\mathrm{hPa}$ level during the TC seasons from 1987 to 2016. The damping and biharmonic diffusion coefficients are set by $1.5 \times 10^{-6} \mathrm{~s}^{-1}$ and $10^{16} \mathrm{~m}^{4} \mathrm{~s}^{-1}$, respectively, which are the same configuration as in Held and Kang (1987).

\section{Results}

To show a possible relationship between a TC in the tropics and Korean air quality, one case, Typhoon Sanvu in 2005, was examined. Here, we looked into the 850-hPa streamfunction associated with Typhoon Sanvu (Fig. 1). The TC passed through the Bashi Channel between Taiwan and the Philippines and made landfall in South China. As seen in the figure, at 1200 UTC 11 August, the TC produced a Rossby wave train from the Bashi Channel to the North Pacific, making an anomalous high over the Korean Peninsula. From 1200 UTC 12 August to 1200 UTC 13 August, the anomalous high strengthens and moves slightly northwestward. At the same time, the other parts of wave train over the North Pacific shifts westward following the movement of Typhoon Sanvu. Consequently, the TC-induced wave propagation had an anomalous high linger over the Korean Peninsula. Notice that the predominant high inhibited efficient diffusion of air pollution by causing a stable boundary layer (Lee et al. 2011, 2013; Seo et al. 2017, 2018; Oh et al. 2018). In addition, the high drove an anomalous westerly between mainland China and the Korean Peninsula, which might have transported air pollutants from the mainland China to the Korean Peninsula and started to increase the $\mathrm{PM}_{10}$ concentration. According to several previous studies, however, the quantitative contribution of transport may
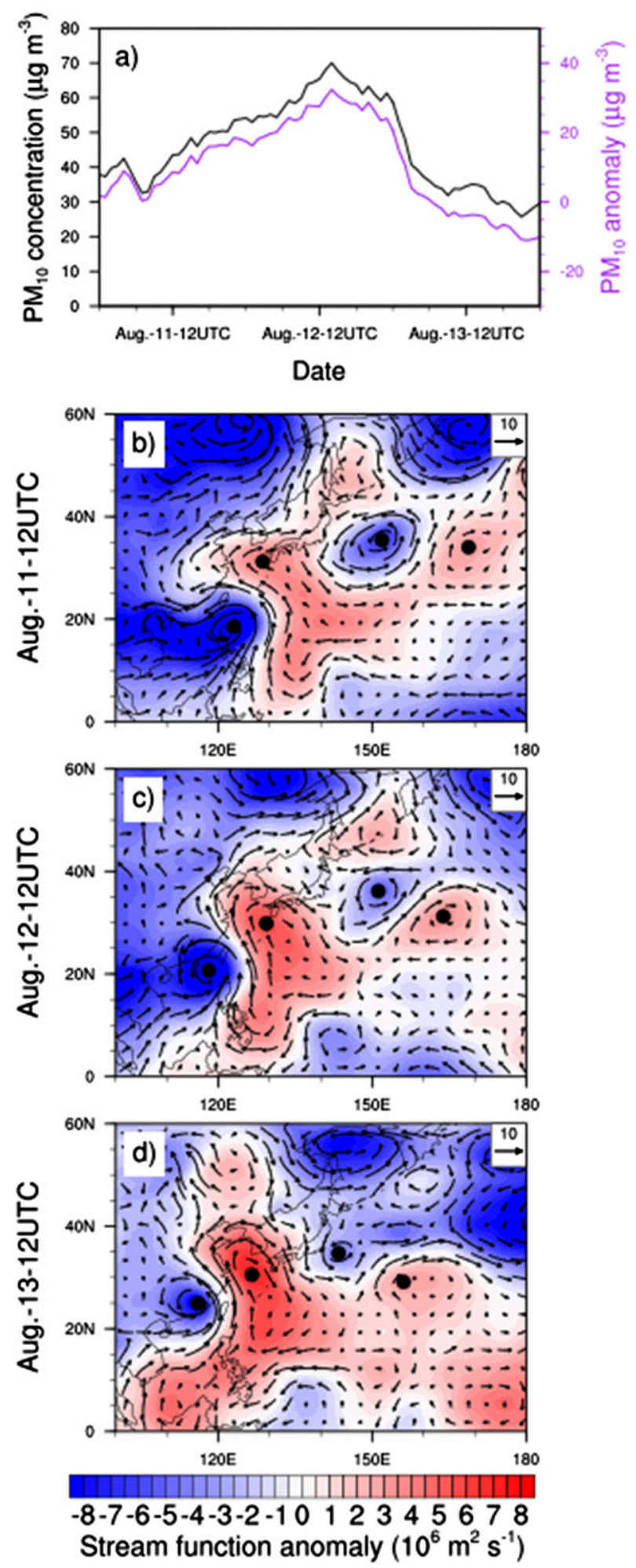

FIG. 1. (a) Lag-time evolution of $\mathrm{PM}_{10}$ concentration over South Korea associated with Typhoon Sanvu in 2005, and anomalies at the $850-\mathrm{hPa}$ streamfunction along with wind-vector anomalies at (b) 1200 UTC 11 Aug, (c) 1200 UTC 12 Aug, and (d) 1200 UTC 13 Aug. Note that 1200 UTC 12 Aug corresponds to the timing of peak $\mathrm{PM}_{10}$. 
be limited considering that the season of interest was summer (e.g., Ghim et al. 2015; Kim et al. 2016). At 1200 UTC 12 August, the $\mathrm{PM}_{10}$ concentration reached maximum. It is noted that in terms of anomaly the concentration exceeds about $30 \mu \mathrm{g} \mathrm{m}^{-3}$ from the climatological value. After that, the concentration began to decrease because a prevailing anomalous southerly mixed polluted air with relatively clean ocean air.

To find a general relation as discussed above, we examined the total number (374) of TCs that formed over the western North Pacific during the analysis period. Figure 2a displays the TC locations when the $\mathrm{PM}_{10}$ concentration over South Korea hit its peak during the lifetime of each TC. Note that the peak timing in this study does not exactly match the actual peak one since the $\mathrm{PM}_{10}$ data were only considered at $0000,0600,1200$, and 1800 UTC. This method, however, could be fine enough to capture the $\mathrm{PM}_{10}$ variation because the frequencies higher than $24 \mathrm{~h}$ of $\mathrm{PM}_{10}$ data were removed. According to the figure, most of the peaks in $\mathrm{PM}_{10}$ concentration are associated with TCs over the South China Sea (SCS). The maximum occurrence frequency of TCs related to high $\mathrm{PM}_{10}$ concentration over South Korea (blue dot in Fig. 2a) is located significantly westward relative to that for random samplings (black dot and crosses in Fig. 2a). Moreover, the region adjacent to the SCS was also thought by Nitta (1987) to be a region in which there is a strong-enough westerly to activate the Rossby wave train. This supports well our hypothesis of a possible remote effect of TCs on the air quality over South Korea. It is likely that a TC induces barotropic forcing over the SCS that excites a planetary Rossby wave that controls the $\mathrm{PM}_{10}$ concentration over the midlatitude countries. On the other hand, other TC locations are not easy to link physically to bad air quality in South Korea. In some cases of TCs passing the Japanese islands, the TCs can interrupt the zonal flow of synoptic weather systems to cause high $\mathrm{PM}_{10}$ concentrations over their west side, as shown in Lee et al. (2013). However, these are much rarer cases than when the TCs go through the SCS. Hence, from this, only the 180 TCs passing through the SCS (a box with dashed line in Fig. 1a) were considered in the analyses hereafter.

To determine if the TCs over the SCS affected the air quality over South Korea and how much the air quality could be degraded due to the TCs, mean hourly variation of the $\mathrm{PM}_{10}$ concentration was analyzed (Fig. 2b). Here, 0 lag hours indicates the time in which the peak $\mathrm{PM}_{10}$ concentration appears during the lifetime of a $\mathrm{TC}$ in the SCS. The gradual increase of the $\mathrm{PM}_{10}$ concentration shown in Fig. $2 \mathrm{~b}$ suggests that air conditions over the country became favorable for air pollution as the TCs approached the SCS. The peak
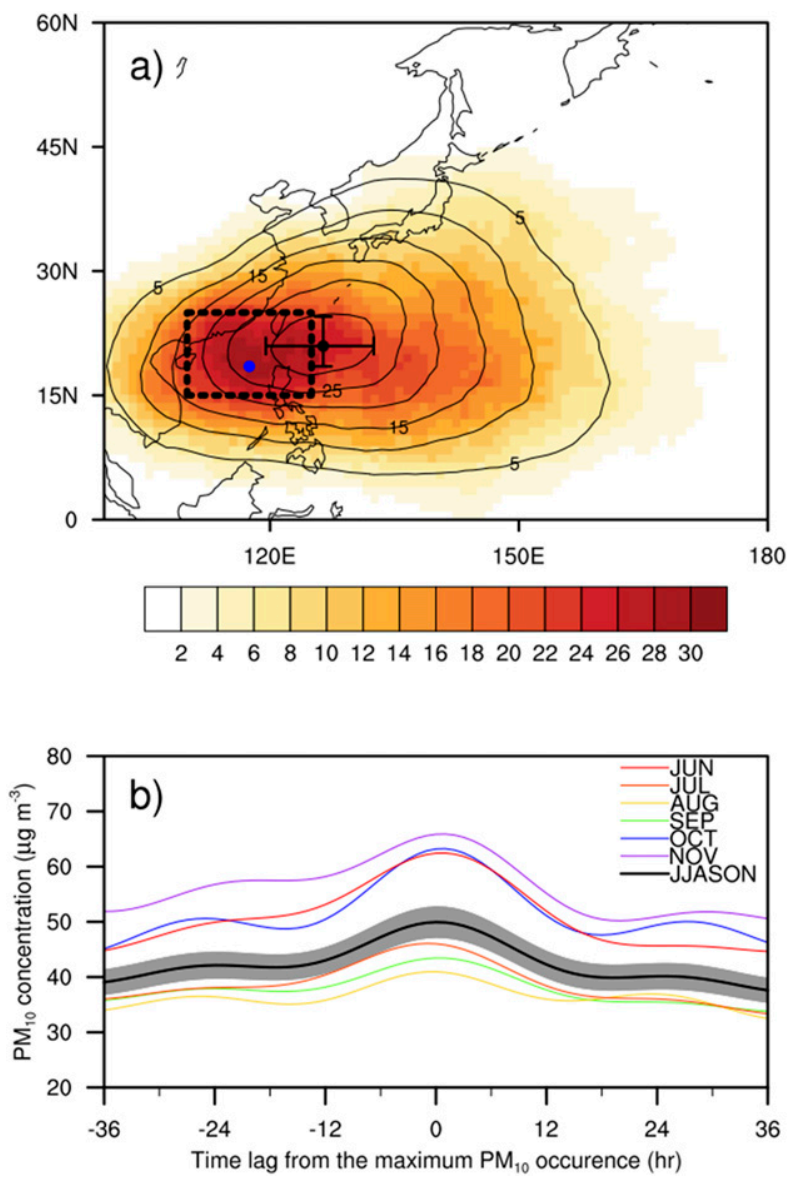

FIG. 2. (a) Spatial distribution of 374 TCs when the peak $\mathrm{PM}_{10}$ concentration is recorded during the lifetime of each TC for the TC seasons (June-November) of 2001-16. The black dashed box outlines the South China Sea. The black dot indicates the grid point where the maximum occurrence frequency of TC appears. To clarify whether the blue dot is statistically significant, we first obtained 1000 random samplings from observations of the 374 TCs. At this point, we did not consider the $\mathrm{PM}_{10}$ concentration over South Korea at all. From each sampling, we got the grid point where the maximum occurrence frequency of TC appears, and then we calculated their average location and $95 \%$ confidence intervals (black dot and error bars). (b) Lag-time evolution of summer mean $\mathrm{PM}_{10}$ concentration over South Korea associated with $180 \mathrm{TCs}$ in the South China Sea (black solid line). The 95\% significance interval is plotted in dark gray. The red, orange, yellow, green, blue, and purple solid lines indicate the $\mathrm{PM}_{10}$ concentrations for June, July, August, September, October, and November, respectively. Note that the monthly climatological $\mathrm{PM}_{10}$ concentrations are 49.3, $38.4,35.0,35.3,45.9,50.7 \mu \mathrm{g} \mathrm{m}^{-3}$ for June, July, August, September, October, and November, respectively. The 0 lag hours indicates the timing of peak $\mathrm{PM}_{10}$ of each TC.

$\mathrm{PM}_{10}$ concentrations at the 0 lag days far exceed the average concentrations for each month. The peak concentration of $\mathrm{PM}_{10}$ for the season mean (JuneNovember) was almost $50 \mu \mathrm{g} \mathrm{m}^{-3}$, which is a guideline value of the World Health Organization. The guideline 
value is an interim target to significantly reduce the risk of bad air quality in South Korea. In addition, about half (i.e., 80 cases) of the TCs in the SCS showed a peak $\mathrm{PM}_{10}$ concentration higher than $50 \mu \mathrm{g} \mathrm{m}^{-3}$ in 0 lag hours. The highest $\mathrm{PM}_{10}$ concentration increases to $65 \mu \mathrm{g} \mathrm{m}^{-3}$ (on average) as the season changes from summer to fall. This is because the background $\mathrm{PM}_{10}$ concentration is higher in fall than in summer. Moreover, $32.4 \%$ of the high- $\mathrm{PM}_{10}$ days between June and November occurred when TCs are located within the SCS. The high-PM $\mathrm{PM}_{10}$ days were defined here as the days in which $\mathrm{PM}_{10}$ concentration exceeds $50 \mu \mathrm{g} \mathrm{m}^{-3}$. Hence, the possible TC-induced poor air quality cannot be totally ignored in terms of its adverse effect on health even though the $\mathrm{PM}_{10}$ concentration is not so extreme.

In Fig. 3, which shows the 850- and 300-hPa streamfunction anomaly maps according to the lag hours defined above, the quasi-stationary Rossby wave pattern is clearly shown with horizontal scales of about 4000 and $2500 \mathrm{~km}$ for the zonal and meridional directions, respectively. Although the vertical alignment between the low and upper levels becomes weak over the Okhotsk Sea after 0 lag hour, they seem still connected with each other as a whole. For -48 lag hours, negative divergence forcing associated with strong convection in the TCs appeared between Taiwan and the Philippines (Fig. S1 in the online supplemental material). Subsequently, clear TC-induced Rossby waves propagated from the SCS to the North Pacific, leading to an anomalous high over the Korean Peninsula. As another possibility, the anomalous high can be associated with conservation of potential vorticity in northeastward airflow on the periphery of a TC. Poleward motion of low-latitude air, conserving absolute vorticity, will generate a negative relative-vorticity anomaly.

As a result, the high anomalies in the lower and upper levels associated with the Rossby waves likely caused a favorable condition for poor air quality over the Korean Peninsula by reducing wind speed and increasing temperature until 0 lag hour. A slow wind speed makes mechanical mixing significantly weaker. High temperature can stimulate photochemical reactions and $\mathrm{SO}_{2}$ oxidation to increase sulfate-type pollutants. Actually, sulfate-type pollutants are most common during summer (Ghim et al. 2015; Kim et al. 2016). In addition, an anomalous westerly flow occurs over the Yellow Sea of South Korea that drives polluted air from over cities of mainland China onto the Korean Peninsula. Consequently, air pollution in South Korea may get worse. This is consistent with the mechanism suggested in several previous studies that TC-induced airflow could make air quality worse (Feng et al. 2007; Chow et al. 2018; Liu et al. 2018). As a TC arrives in the SCS, the Rossby waves move westward; hence South Korea is covered by a high pressure anomaly at 0 lag hours, which results in the highest $\mathrm{PM}_{10}$ concentration. For +24 lag hours, an anomalous southerly brought in cleaner air from the ocean, improving air quality over South Korea. For +48 lag hours, the Rossby wave train in the $850-\mathrm{hPa}$ level becomes significantly weak, while that in the $300-\mathrm{hPa}$ level is still evident. The $\mathrm{PM}_{10}$ concentration is already back to its normal state.

On the other hand, as a brief assessment of the contribution of air pollutant advection, the HYSPLIT trajectory model was applied to 180 TCs (Stein et al. 2015; Rolph et al. 2017). According to the model, 79 polluted cases' back trajectories originated from the mainland China, suggesting that about $40 \%$ of the cases are possibly associated with advection from China (Fig. S2 in the online supplemental material). Although this is a very simple approach, it is consistent with some previous studies arguing $40 \%-70 \%$ of air pollutants in South Korea are attributable to long-range transport from China (Lee et al. 2011; Kim et al. 2017; Choi et al. 2019).

According to our observational analyses, it is possible for a TC to affect air quality over a midlatitude country via Rossby wave excitation. To support this, a model experiment was performed using a simple barotropic model (Held and Kang 1987) since the vertical structure of TC-induced Rossby waves is almost barotropic, as shown in Fig. 3. Here, because we are more interested in the low-level circulation, the $850-\mathrm{hPa}$ level was examined. The origin and propagation of Rossby waves are determined by the distributions of divergence forcing and background flow (Figs. 4a,b). We set a Gaussian distribution of divergence forcing in the SCS area $\left(15^{\circ}-25^{\circ} \mathrm{N}\right.$ and $\left.110^{\circ}-125^{\circ} \mathrm{E}\right)$. According to the observations, the average value of divergence (i.e., $D$ ) in this region was $-1.03 \times 10^{-6} \mathrm{~s}^{-1}$ from -24 to +24 lag hours. The absolute vorticity (i.e., $f+\zeta$ ) in midlatitudes is generally on the order of $10^{-4} \mathrm{~s}^{-1}$. Therefore, the average divergence forcing (i.e., $[f+\zeta] D)$ in the SCS was set to $-1.00 \times 10^{-10} \mathrm{~s}^{-2}$. The background flow (i.e., climatological mean winds at $850 \mathrm{hPa}$ ) presents clear meridional variation of the zonal flow, which is at its maximum near $40^{\circ} \mathrm{N}$ and at its minimum near $20^{\circ} \mathrm{N}$.

The model results shown in Fig. 4c well support our observational analyses. A Rossby-wave-like circulation from the SCS to the Korean Peninsula develops within 2 days. The weak response in the Okhotsk Sea is equivalent to the obscure low anomaly in the observation (left panel of Fig. 3). Because our experiment was based on a TC for only 0 lag days, it could not reflect westward movement of the TC. However, it indicates that the barotropic forcing over the SCS causes a noticeable high pressure anomaly over the Korean 

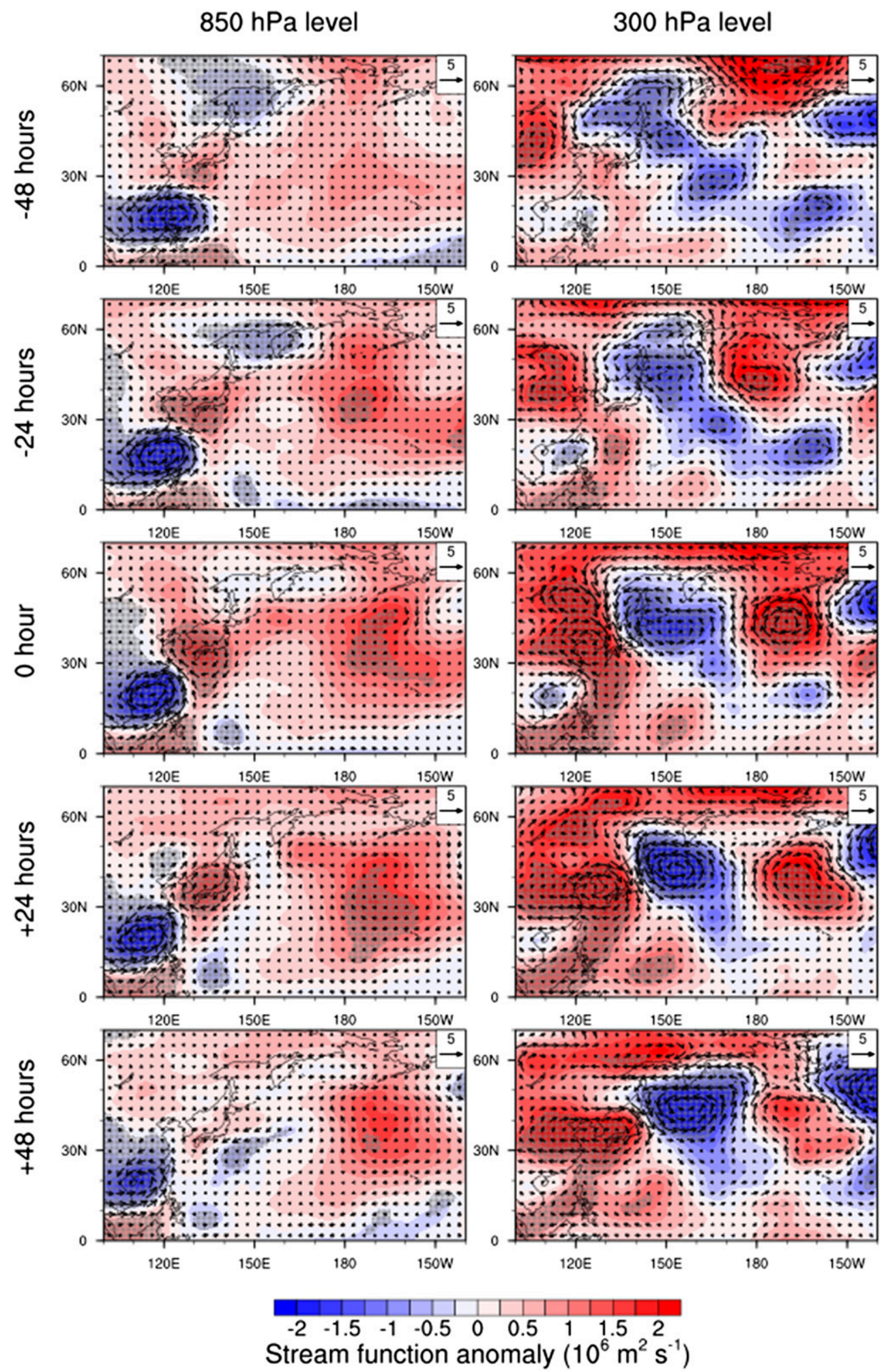

FIG. 3. Lag-time evolution of average (left) 850- and (right) 300-hPa streamfunction anomalies with windvector anomalies $\left(10^{6} \mathrm{~m}^{2} \mathrm{~s}^{-1}\right.$ and $\left.\mathrm{m} \mathrm{s}^{-1}\right)$ for $180 \mathrm{TCs}$ in the South China Sea. Texture shades indicate that the streamfunction anomalies are statistically significant at the $95 \%$ confidence level. Statistical significance was tested using the Monte Carlo method with 1000 random samples. Note that 0 lag hours indicates the timing of the peak $\mathrm{PM}_{10}$ of each TC. 


\section{a) Divergence forcing $\left(10^{-10} \mathrm{~s}^{-2}\right)$}

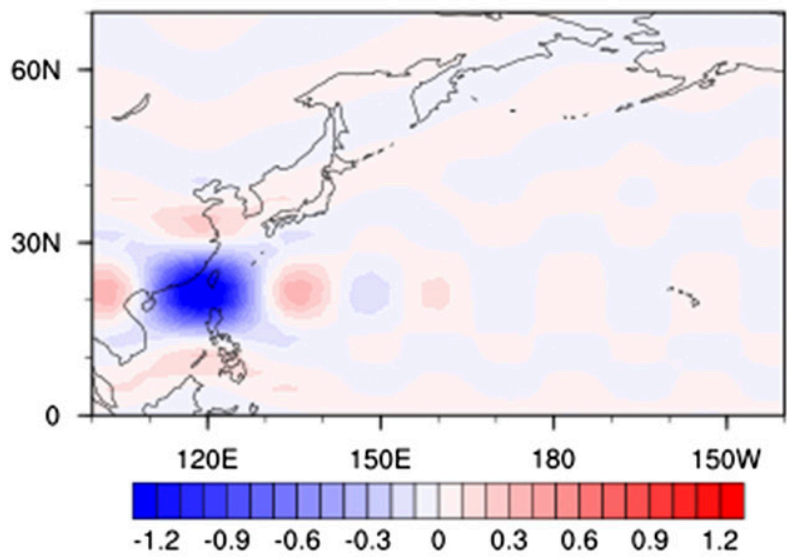

b) Background flows at $850 \mathrm{hPa}\left(\mathrm{m} \mathrm{s}^{-1}\right)$

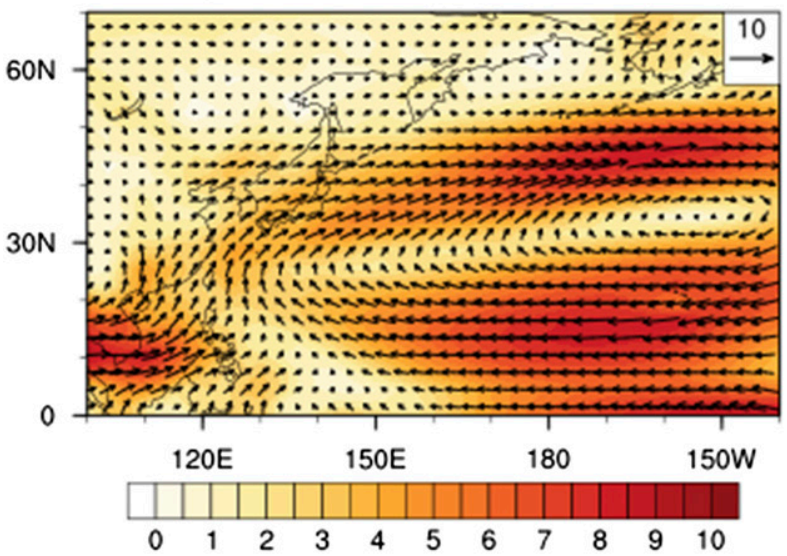

C) Stream fucntion after 48 hours $\left(10^{6} \mathrm{~m}^{2} \mathrm{~s}^{-1}\right)$

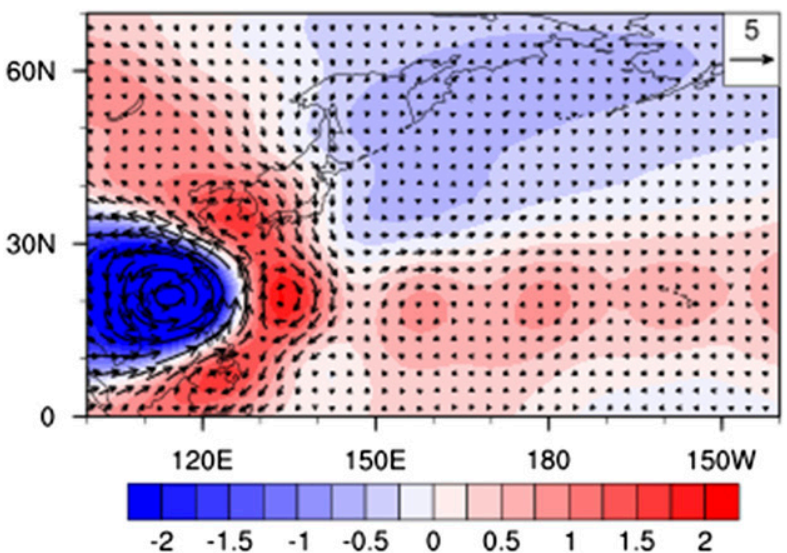

FIG. 4. Results from a barotropic model's initial conditions: (a) divergence forcing $\left(10^{-6} \mathrm{~s}^{-1}\right)$, (b) 850 -hPa climatological wind speed and vectors for TC seasons of the analysis period $\left(10 \mathrm{~m} \mathrm{~s}^{-1}\right)$, and (c) stream function with wind vectors after a 48 -h run $\left(10^{6} \mathrm{~m}^{2} \mathrm{~s}^{-1}\right.$ and $10 \mathrm{~m} \mathrm{~s}^{-1}$, respectively).
Peninsula through a poleward propagation of the Rossby wave train. It is also notable that the magnitude of the streamfunction anomaly of the Rossby waves in the model is similar to that in the observation, although the simulation is simple and idealized.

\section{Concluding remarks}

This study is the first to suggest a possible remote effect of TC activity in the tropics on air quality in a midlatitude East Asian country, South Korea. The air quality over South Korea is likely influenced by TCs in the SCS through a quasi-stationary Rossby waves. This mechanism is similar to that by which TCs in the tropics can modulate weather in midlatitude East Asia (Kawamura and Ogasawara 2006; Yamada and Kawamura 2007). Strong divergence forcing due to TC in the SCS can excite poleward-propagating Rossby waves from the SCS to the North Pacific. A high pressure anomaly lingering over the Korean Peninsula could change airflow and stability that could increase the $\mathrm{PM}_{10}$ concentration up to $65 \mu \mathrm{g} \mathrm{m}^{-3}$ over the country. As another possibility, the anomalous high can be generated by poleward migration of lowlatitude air to conserve absolute vorticity. Our ideal model experiment also clearly suggests that a TC-induced Rossby waves could produce an anomalous high over the Korean Peninsula. The peak $\mathrm{PM}_{10}$ concentrations owing to TCs were not extreme in this study, but in most cases they were still over $50 \mu \mathrm{g} \mathrm{m}^{-3}$, a guideline value of the World Health Organization. The relatively low $\mathrm{PM}_{10}$ concentration due to TCs could be because air quality in summer is basically much better than that in winter over the Northern Hemisphere due to less pollutant emission and unstable air conditions (Lee et al. 2011). Actually, in our results, the $\mathrm{PM}_{10}$ concentration remarkably increases as the season changes to fall. Thus, it is suggested that TC activity in the tropics, as well as midlatitude synoptic systems, should be considered for more accurate forecasts of air quality.

Acknowledgments. This study was funded by the Korea Meteorological Administration Research and Development Program under KMI2018-07510 and KMI2018-03413.

\section{REFERENCES}

Anderson, J. O., J. G. Thundiyil, and A. Stolbach, 2012: Clearing the air: A review of the effects of particulate matter air pollution on human health. J. Med. Toxicol., 8, 166-175, https:// doi.org/10.1007/s13181-011-0203-1.

Camino, C., and Coauthors, 2015: An empirical equation to estimate mineral dust concentrations from visibility observations in northern Africa. Aeolian Res., 16, 55-68, https://doi.org/ 10.1016/j.aeolia.2014.11.002.

Chen, J.-P., I.-J. Chen, and I.-C. Tsai, 2016: Dynamic feedback of aerosol effects on the East Asian summer monsoon. J. Climate, 29, 6137-6149, https://doi.org/10.1175/JCLI-D-15-0758.1. 
Choi, J., and Coauthors, 2019: Impacts of local vs. trans-boundary emissions from different sectors on PM2.5 exposure in South Korea. Atmos. Environ., 203, 196-205, https://doi.org/10.1016/ j.atmosenv.2019.02.008.

Chow, E. C. H., R. C. Y. Li, and W. Zhou, 2018: Influence of tropical cyclones on Hong Kong air quality. Adv. Atmos. Sci., 35, 1177-1188, https://doi.org/10.1007/s00376-018-7225-4.

Dee, D. P., and Coauthors, 2011: The ERA-Interim reanalysis: Configuration and performance of the data assimilation system. Quart. J. Roy. Meteor. Soc., 137, 553-597, https://doi.org/10.1002/qj.828.

Farmer, A. M., 1993: The effects of dust on vegetation-A review. Environ. Pollut., 79, 63-75, https://doi.org/10.1016/ 0269-7491(93)90179-R.

Feng, Y., A. Wang, D. Wu, and X. Xu, 2007: The influence of tropical cyclone Melor on $\mathrm{PM}_{10}$ concentrations during an aerosol episode over the Pearl River Delta region of China: Numerical modeling versus observational analysis. Atmos. Environ., 41, 4349-4365, https://doi.org/10.1016/j.atmosenv.2007.01.055.

Ghim, Y. S., Y.-S. Chang, and K. Jung, 2015: Temporal and spatial variations in fine and coarse particles in Seoul, Korea. Aerosol Air Qual. Res., 15, 842-852, https://doi.org/10.4209/aaqr.2013.12.0362.

Harrison, R. M., and J. Yin, 2000: Particulate matter in the atmosphere: Which particle properties are important for its effects on health? Sci. Total Environ., 249, 85-101, https://doi.org/ 10.1016/S0048-9697(99)00513-6.

Held, I. M., and I.-S. Kang, 1987: Barotropic models of the extratropical responses to El Niño. J. Atmos. Sci., 44, 3576-3586, https://doi.org/10.1175/1520-0469(1987)044<3576: BMOTER $>2.0 . \mathrm{CO} ; 2$.

Hong, Y. C., J. T. Lee, H. Kim, E. H. Ha, J. Schwartz, and D. C. Christiani, 2002: Effects of air pollutants on acute stroke mortality. Environ. Health Perspect., 110, 187-191, https:// doi.org/10.1289/ehp.02110187.

Huang, Y., R. E. Dickinson, and W. L. Chameides, 2006: Impact of aerosol indirect effect on surface temperature over East Asia. Proc. Natl. Acad. Sci. USA, 103, 4371-4376, https://doi.org/ 10.1073/pnas.0504428103.

_ W. W. Chameides, and R. E. Dickinson, 2007: Direct and indirect effects of anthropogenic aerosols on regional precipitation over East Asia. J. Geophys. Res., 112, D03212, https://doi.org/10.1029/2006JD007114.

Hyslop, N. P., 2009: Impaired visibility: The air pollution people see. Atmos. Environ., 43, 182-195, https://doi.org/10.1016/ j.atmosenv.2008.09.067.

Jiang, Y., X. Liu, X.-Q. Yang, and M. Wang, 2013: A numerical study of the effect of different aerosol types on East Asian summer clouds and precipitation. Atmos. Environ., 70, 51-63, https://doi.org/10.1016/j.atmosenv.2012.12.039.

Kawamura, R., and T. Ogasawara, 2006: On the role of typhoons in generating PJ teleconnection patterns over the western North Pacific in late summer. SOLA, 2, 37-40, https://doi.org/ 10.2151/SOLA.2006-010.

Kim, B. M., J. Seo, J. Y. Kim, J. Y. Lee, and Y. Kim, 2016: Transported vs. local contributions from secondary and biomass burning sources to $\mathrm{PM}_{2.5}$. Atmos. Environ., 144, 24-36, https://doi.org/10.1016/j.atmosenv.2016.08.072.

Kim, B.-U., C. Bae, H. C. Kim, E. Kim, and S. Kim, 2017: Spatially and chemically resolved source appointment analysis: Case study of high particulate matter event. Atmos. Environ., 162, 55-70, https://doi.org/10.1016/j.atmosenv.2017.05.006.

Lau, K.-M., and Coauthors, 2008: The Joint Aerosol-Monsoon Experiment. Bull. Amer. Meteor. Soc., 89, 369-384, https:// doi.org/10.1175/BAMS-89-3-369.
Lee, S., C.-H. Ho, and Y.-S. Choi, 2011: High-PM ${ }_{10}$ concentration episodes in Seoul, Korea: Background sources and related meteorological conditions. Atmos. Environ., 45, 7240-7247, https://doi.org/10.1016/j.atmosenv.2011.08.071.

$\longrightarrow,-$, Y. G. Lee, H.-J. Choi, and C.-K. Song, 2013: Influence of transboundary air pollutants from China on the high-PM $\mathrm{PM}_{10}$ episode in Seoul, Korea for the period October 16-20, 2008. Atmos. Environ., 77, 430-439, https://doi.org/10.1016/j.atmosenv.2013.05.006.

Li, R. C. Y., W. Zhou, and T. Li, 2014: Influences of the PacificJapan teleconnection pattern on synoptic-scale variability in the western North Pacific. J. Climate, 27, 140-154, https:// doi.org/10.1175/JCLI-D-13-00183.1.

Li, W., Y. Cao, R. Li, X. Ma, J. Chen, Z. Wu, and Q. Xu, 2018: Spatial variation in the effects of air pollution on cardiovascular mortality in Beijing, China. J. Expo. Sci. Environ. Epidemiol., 28, 297-304, https://doi.org/10.1038/jes.2016.21.

Liu, W., Y. Han, Y. Yin, J. Duan, J. Gong, Z. Liu, and W. Xu, 2018: An aerosol air pollution episode affected by binary typhoons in east and central China. Atmos. Pollut. Res., 9, 634-642, https://doi.org/10.1016/j.apr.2018.01.005.

Nitta, T., 1987: Convective activities in the tropical western Pacific and their impact on the Northern Hemisphere summer circulation. J. Meteor. Soc. Japan, 65, 373-390, https://doi.org/ 10.2151/jmsj1965.65.3_373.

Oh, H.-R., Y.-S. Choi, C.-H. Ho, and M.-J. Jeong, 2013: Estimation of aerosol direct radiative effects for all-sky conditions from CERES and MODIS observations. J. Atmos. Sol.-Terr. Phys., 102, 311-320, https://doi.org/10.1016/j.jastp.2013.06.009.

_ C.-H. Ho, D.-S. R. Park, J. Kim, C.-K. Song, and S.-K. Hur, 2018: Possible relationship of weakened Aleutian low with air quality improvement in Seoul, South Korea. J. Appl. Meteor. Climatol, 57, 2363-2373, https://doi.org/10.1175/JAMC-D-17-0308.1.

Pope, C. A., III, and D. W. Dockery, 2006: Health effects of fine particulate air pollution: Lines that connect. J. Air Waste Manage. Assoc., 56, 709-742, https://doi.org/10.1080/10473289.2006.10464485.

Rolph, G., A. Stein, and B. Stunder, 2017: Real-time Environmental Applications and Display sYstem: READY. Environ. Modell. Software, 95, 210-228, https://doi.org/10.1016/j.envsoft.2017.06.025.

Seo, J., J. Y. Kim, D. Youn, J. Y. Lee, H. Kim, Y. B. Lim, Y. Kim, and H. C. Jin, 2017: On the multiday haze in the Asian continental outflow: The important role of synoptic conditions combined with regional and local sources. Atmos. Chem. Phys., 17, 9311-9332, https://doi.org/10.5194/acp-17-9311-2017.

—, D.-S. R. Park, J. Y. Kim, D. Youn, Y. B. Lim, and Y. Kim, 2018: Effects of meteorology and emissions on urban air quality: A quantitative statistical approach to long-term records (1999-2016) in Seoul, South Korea. Atmos. Chem. Phys., 18, 16 121-16137, https://doi.org/10.5194/acp-18-16121-2018.

Shin, D. C., 2007: Health effects of ambient particulate matter. J. Korean Med. Assoc., 50, 175-182, https://doi.org/10.5124/jkma.2007.50.2.175.

Stein, A. F., R. R. Draxler, G. D. Rolph, B. J. Stunder, M. D. Cohen, and F. Ngan, 2015: NOAA's HYSPLIT atmospheric transport and dispersion modeling system. Bull. Amer. Meteor. Soc., 96, 2059-2077, https://doi.org/10.1175/BAMS-D-14-00110.1.

Yamada, K., and R. Kawamura, 2007: Dynamical link between typhoon activity and the PJ teleconnection pattern from early summer to autumn as revealed by the JRA-25 reanalysis. SOLA, 3, 65-68, https://doi.org/10.2151/SOLA.2007-017.

Yang, J. X., A. K. H. Lau, J. C. H. Fung, W. Zhou, and M. Wenig, 2012: An air pollution episode and its formation mechanism during the tropical cyclone Nuri's landfall in a coastal city of south China. Atmos. Environ., 54, 746-753, https://doi.org/ 10.1016/j.atmosenv.2011.12.023. 